\title{
Arteritic Anterior Ischemic Optic Neuropathy Associated with Giant-Cell Arteritis in Korean Patients: A Retrospective Single-Center Analysis and Review of the Literature
}

\author{
Jae-Hwan Choi ${ }^{\mathrm{a}, \mathrm{b} *}$ \\ Jong Hoon Shin ${ }^{\mathrm{b}, \mathrm{c*}}$ \\ Jae Ho Jung ${ }^{d}$ \\ ${ }^{a}$ Departments of Neurology and \\ 'Ophthalmology, Pusan National University \\ Yangsan Hospital, Yangsan, Korea \\ ${ }^{b}$ Research Institute for Convergence \\ of Biomedical Science and Technology, \\ Pusan National University \\ Yangsan Hospital, Yangsan, Korea \\ 'Department of Ophthalmology, \\ Seoul National University \\ College of Medicine, Seoul, Korea
}

\begin{abstract}
Background and Purpose The aim of this study is to report the relative incidence of arteritic anterior ischemic optic neuropathy (AAION) associated with giant-cell arteritis (GCA) in a single-center and evaluate the clinical features of AAION in Korean patients.

Methods The medical records of patients with presumed AION who visited our hospital from January 2013 to August 2018 were examined retrospectively. The patients were divided into two groups: AAION associated with GCA, and non AION (NAION). We additionally reviewed the literature and identified all cases of AAION in Korean and Caucasian patients. We evaluated the clinical data including the initial and final best-corrected visual acuities, fundus photographs, visual field tests, fluorescein angiography, and contrast-enhanced MRI, and compared the data with those for Caucasian patients in the literature.

Results Of the 142 patients with presumed AION, 3 (2.1\%) were diagnosed with AAION and 139 (97.9\%) were diagnosed with NAION. Seven Korean patients with AAION associated with GCA were identified in our data and the literature review. We found no difference in any clinical features other than laterality: four of the seven Korean patients had bilateral involvement. Moreover, the optic nerve sheath was enhanced in two of our Korean patients.

Conclusions AAION associated with GCA is a very rare condition compared to NAION in Korea. However, GCA should be considered in all cases of ischemic optic neuropathy because AAION is associated with poor visual outcome, and sometimes presents bilaterally.

Key Words arteritic anterior ischemic optic neuropathy, giant-cell arteritis, Korea, nonarteritic ischemic optic neuropathy, optic nerve sheath enhancement, anterior ischemic optic neuropathy.
\end{abstract}

Received January 11, 2019

Revised March 17, 2019

Accepted March 19, 2019

\section{Correspondence}

Jae Ho Jung, MD, $\mathrm{PhD}$

Department of Ophthalmology,

Seoul National University

College of Medicine,

101 Daehak-ro, Jongno-gu,

Seoul 03080, Korea

Tel $+82-2-2072-1765$

Fax $+82-2-747-5130$

E-mail jaeho.jung@snu.ac.kr

*These authors contributed equally to this work.

\section{INTRODUCTION}

Giant-cell arteritis (GCA), also known as temporal arteritis, is an autoimmune vasculitis of moderate-sized and large blood vessels that is considered a medical emergency due to its potential to cause rapidly progressive irreversible blindness. ${ }^{1,2}$ The most common pattern of permanent vision loss due to GCA is arteritic anterior ischemic optic neuropathy (AAION) ${ }^{3,4}$

GCA is common in the Caucasian population, ${ }^{1}$ but its prevalence seems to be extremely low in the Asian population. ${ }^{5,6}$ The incidence of GCA is unknown in Korea, with only a few case reports having been published..$^{7-11}$ Physicians and ophthalmologists therefore widely believe that cases of AAION associated with GCA are extremely rare in Asian populations. Unfortunately this belief may occasionally lead to misdiagnosis and consequent permanent vision loss, which sometimes occurs bilaterally.

( $)$ This is an Open Access article distributed under the terms of the Creative Commons Attribution Non-Commercial License (https://creativecommons.org/licenses/by-nc/4.0) which permits unrestricted non-commercial use, distribution, and reproduction in any medium, provided the original work is properly cited. 
The aims of this study were to estimate the incidence of AAION associated with GCA among patients with presumed AION in a single medical center in Korea, and to delineate the distinctive clinical features of AAION associated with GCA in Korean patients based on our own case series and cases reported in the literature.

\section{METHODS}

\section{Subjects}

Consecutive cases of AAION associated with GCA among the patients with presumed AION who visited the neuro-ophthalmology clinic at Pusan National University Yangsan Hospital from January 2013 through August 2018 were analyzed retrospectively. This study was reviewed and approved by the Institutional Review Board of Pusan Nation University Yangsan Hospital, Yangsan, South Korea (approval no. 05-2018188). All study procedures adhered to the tenets of the Declaration of Helsinki.

Patients were diagnosed with presumed AION [both AAION and non AION (NAION)] if all of the following criteria were present or true: 1) an age at onset of $>50$ years, 2) acute optic neuropathy (sudden onset of decreased visual acuity and/or abnormal visual field consistent with ischemic optic neuropathy with a relative afferent pupillary defect) within the previous 14 days, 3) pale or hyperemic optic disc swelling and/or delayed choroidal filling demonstrated in fluorescein angiography, and 4) all other possible causes of acute optic neuropathy excluded, including optic nerve tumor, retinal vessel occlusion, autoimmune disease, inflammatory conditions, cancer masquerade syndromes, and other infectious etiologies. ${ }^{12,13}$

We additionally classified AAION and presumed NAION in this study cohort as follows. AAION associated with GCA was diagnosed if three or more of the following GCA diagnostic criteria were met: ${ }^{14} 1$ ) age at onset of $>50$ years, 2) newonset headache, 3 ) temporal artery abnormality as indicated by tenderness or reduced pulsation in a physical examination, 4) elevated erythrocyte sedimentation rate (ESR) of $>50 \mathrm{~mm} / \mathrm{h}$, and 5) abnormal temporal arterial biopsy findings indicating necrotizing vasculitis with predominant mononuclear cell infiltration or granulomatous inflammation. The other patients with ischemic optic neuropathy who did not fulfill the GCA diagnostic criteria were diagnosed as presumed NAION.

We investigated medical records to determine the presence of systemic illness, and reviewed the presenting symptoms and/or signs of AAION. We evaluated the initial and final best-corrected visual acuities (BCVA), intraocular pressure, slit-lamp biomicroscopy findings, dilated fundus examination findings, Humphrey visual field test results, and optic disc and fundus photographs (Kowa Co., Tokyo, Japan) at each follow-up visit in the patients with AAION associated with GCA. The findings of fundus fluorescein angiography, indocyanine green angiography, and contrast-enhanced MRI of the brain and orbit were also reviewed for the patients with AAION.

\section{Literature search and review}

The PubMed, MEDLINE, Google Scholar, and Research Information Sharing Service (www.riss.kr) databases were searched in October 2018. Papers containing the terms 'arteritic anterior ischemic optic neuropathy' or 'giant cell arteritis' in the main text, 'Korean' in the title or abstract, and 'Korea' in the affiliation of the corresponding author were identified. We also conducted a literature search to identify Caucasian AAION patients, and compared the data of the Korean and Caucasian cohorts.

\section{RESULTS}

\section{Incidence of AAION associated with GCA at a single medical center in Korea}

The medical records of 142 patients with AION were collected from the clinical medical record search program provided by Pusan National University Hospital, and the medical records of all patients were reviewed. Three patients $(2.1 \%)$ were finally diagnosed with AAION: two (cases 5 and 7) had biopsy-confirmed GCA, and one (case 6) met the GCA diagnostic criteria (new-onset headache, elevated ESR, and tenderness in the temporal area). The median age of the patients with AAION was 75 years (range, 68-81 years), and all of them were female. Two had bilateral AAION. The median visual acuity of the affected eye was 20/2,000 at the initial visit [range, no light perception (NLP) to 20/80] and 20/2,000 at the final visit (range, NLP to 20/100).

The demographic and baseline characteristics of the patients with AAION associated with GCA in our study group are provided in Table 1. Presumed NAION was diagnosed in $139(97.9 \%)$ patients. These patients had a median age of 68 years (range, 50-96 years), $76(54.7 \%)$ of them were female, and $5(3.6 \%)$ had bilateral involvement. The median visual acuities of the affected eye at the initial and final visits were 20/100 (range, NLP to 20/25) and 20/63 (range, NLP to $20 / 20$ ), respectively.

\section{Clinical features of AAION associated with GCA in Korean patients}

Five Korean patients with AAION associated with biopsyconfirmed GCA were identified in the literature review, one of whom was included in the cohort of the current study. Two 
other patients with AAION associated with GCA from our study cohort were identified in the literature search. Eleven eyes of seven patients with AAION associated with GCA were evaluated. Because our study included consecutive patients during the research period, one previously reported case (case 5) was included in this investigation.

The clinical features and treatment outcomes are presented in Table 1 . The 11 eyes comprised 2 patients with the simultaneous onset of bilateral AAION, 2 patients who developed contralateral vision loss after $2-4$ weeks, and 3 patients who had unilateral involvement only. Five patients $(71.4 \%)$ had severe vision loss (BCVA of <20/200) at the initial visit. In these cases the optic disc appeared chalky and swollen, but neither peripapillary hemorrhages nor hard exudations were found. The retinal cotton spot was observed in four eyes, and retinal artery occlusion or narrowing was observed in three eyes (Fig. 1, 27.3\%). Typical systemic symptoms associated with GCA were present before and at the time of vision loss in six patients (85.7\%), including headache and at least one of the following symptoms: scalp tenderness, jaw claudication, fever and general malaise, and anorexia and weight loss. One patient presented with occult GCA; that is, no systemic symptoms or signs. One patient presented with scalp necrotic lesions (Fig. 1). No patients complained of diplopia. Contrast-enhanced MRI of the orbit revealed abnormal enhancement along the bilateral optic nerve sheath (ONS) in two patients (cases 6 and 7). The mean ESR was $71.4 \mathrm{~mm} / \mathrm{h}$ (range, 49-126 $\mathrm{mm} / \mathrm{h}$ ) and the mean C-reactive protein level was $8.48 \mathrm{mg} / \mathrm{L}$ (range, 3.04-18.23 mg/L). High-dose intravenous methylprednisolone and subsequent oral corticosteroids with tapering was administered in all cases. The follow-up period ranged from 3 to 12 months. At the final follow-up, the disc edema had resolved in all eyes and the ESR had normalized, but there was a significant improvement of $\geq 2$ lines in the visual acuity in only one eye $(9.0 \%)$. All patients eventually developed diffuse optic atrophy in the affected eyes, and four patients were considered legally blind (57.1\%).

\section{DISCUSSION}

The true prevalence rates of AAION and NAION in Korea could not be concluded from our data, but we found a markedly lower relative incidence of AAION (2.1\%) compared to NAION (97.9\%). The clinical manifestations of AAION associated with GCA in Korean patients were similar to those described previously, with the exception of the laterality (Table 2).

Epidemiology is an important tool for assessing risk and the genetic or environmental relationships while considering the likelihood of a range of differential diagnoses. GCA is the most common systemic vasculitis in patients aged $>50$ years, and the prevalence of GCA is lower in Asian than Caucasian populations. ${ }^{6}$ Pereira et al. ${ }^{5}$ reported this finding for a United States population, and concluded that the etiology of GCA is more strongly associated with the genetic background than environmental influences. Hayreh ${ }^{15}$ analyzed a large data set for a predominantly Caucasian clinicbased cohort to reveal prevalence rates of $10 \%$ and $90 \%$ for AAION and NAION, respectively. In contrast, Gruener et al. ${ }^{16}$ reported a markedly lower prevalence for AAION vs. NAION in an Arab population, of $2.3 \%$ vs. $97.7 \%$, respectively; these values are similar to our current data. This discrepancy between Caucasians and Arabs may indicate that the prevalence of GCA varies with race.

All patients in the current study who were older than 60 years presented with the rapid onset of severe vision loss and developed the typical pallid 'chalky white' disc edema. In particular, these ocular findings (i.e., chalky white disc swelling with or without retina ischemia) were a distinctive feature of the patients with AAION. We therefore suggest that a detailed fundus examination could be beneficial for the differential diagnosis of patients with NAION. Typical systemic symptoms of GCA were present in most of the patients, and headache, jaw claudication, and malaise were common symptoms in our Korean patients with GCA. However, one patient had occult GCA, with the ocular involvement of GCA but without any systemic symptoms or signs of GCA. Hayreh et al. ${ }^{3}$ reported that GCA should be considered in persons aged $>55$ years with amaurosis fugax or vision loss, the development of acute ocular ischemia, and abnormal C-reactive protein levels with or without an elevated ESR and systemic symptoms, because $21.2 \%$ of GCA patients had occult presentations.

GCA has recently been recognized as a systemic vascular disease that is not confined to the ocular arteries. ${ }^{17}$ Previous studies have demonstrated that approximately one-third of patients with GCA develop serious peripheral vascular disease during long-term follow-up, ${ }^{18}$ and there is a growing body of evidence that unrecognized extraocular involvement could be even more common. One patient in our cohort had scalp necrosis as an extraocular involvement, and this in association with GCA is associated with a higher risk of vision loss and a higher mortality rate compared to GCA without scalp necrosis. ${ }^{19,20}$ In addition, scalp necrosis after steroid treatment may indicate an inadequate steroid dosage. ${ }^{20}$ Therefore, scalp necrosis in GCA should be considered as a more-aggressive disease process and treated with a sufficient dose of steroid to prevent a poor prognosis. As in result, we recommend that regular workups for systemic vascular complications as well as ocular complications should be performed in patients with AAION as- 


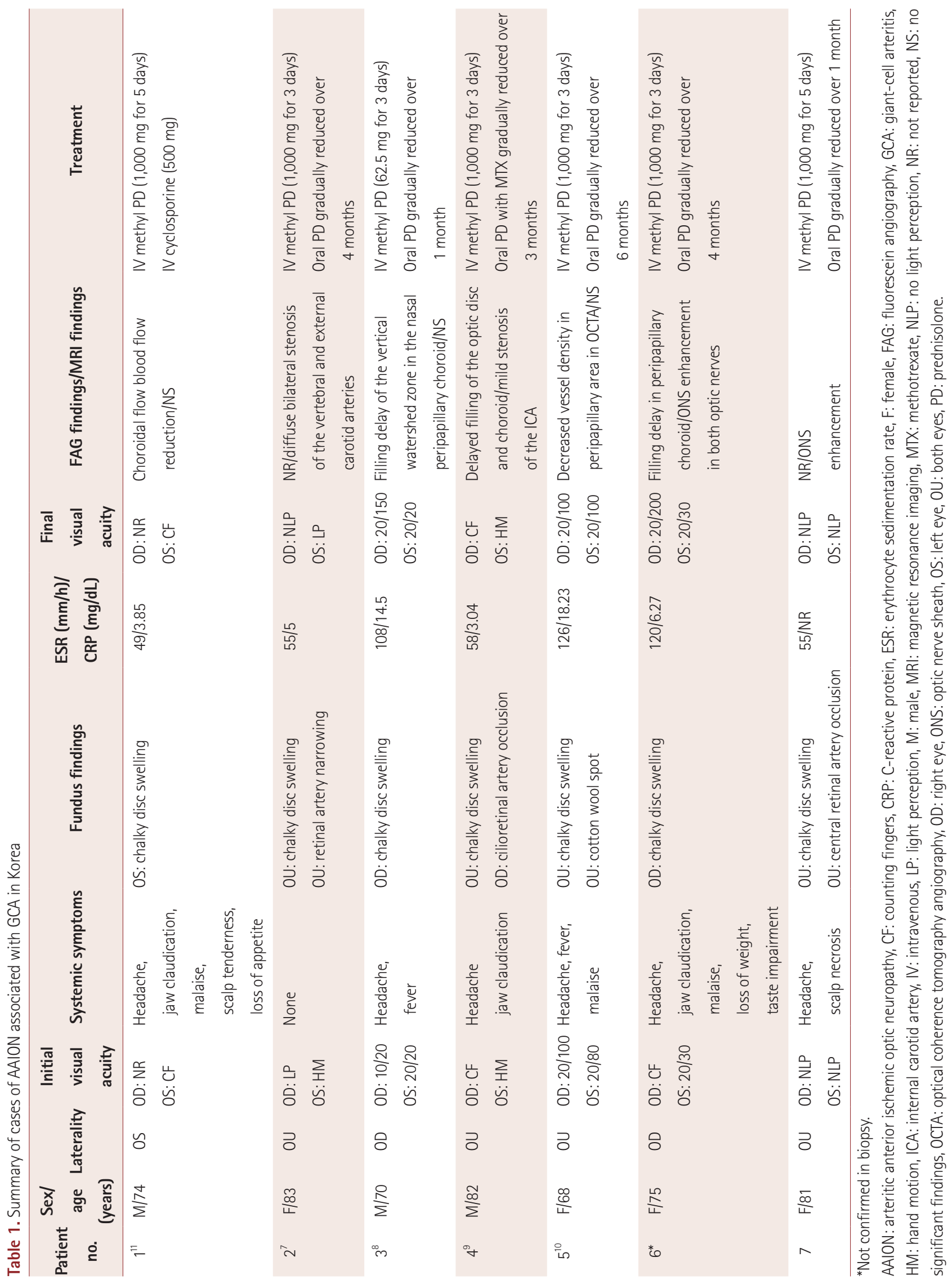



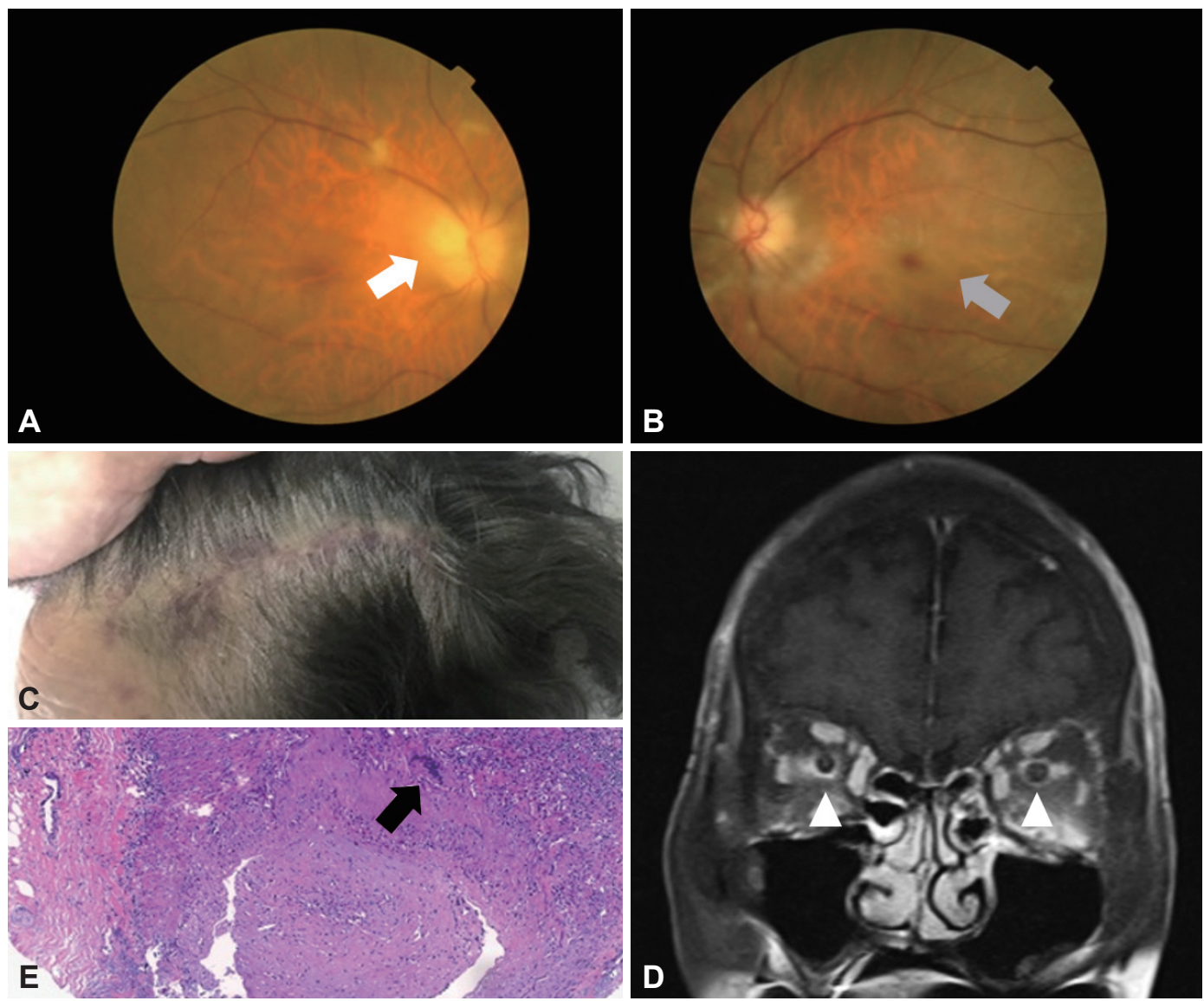

Fig. 1. Clinical findings in case 7. Fundus photographs revealed chalky optic disc swelling with cotton wool spots in the right eye (arrow, A) and pale optic disc swelling with ischemic macular edema and central retinal artery occlusion (arrow, B). C: Multiple purpuric skin lesions were observed in the frontoparietal scalp area. D: Bilateral optic nerve sheath enhancement was observed in contrast-enhanced orbital MRI (arrowheads). E: Histology revealed giant cells (arrow), lymphohistiocytic cells infiltration, and arterial wall thickening with elastic fiber fragmentation. Hematoxylin-eosin staining $(\times 40)$.

sociated with GCA.

Contrast-enhanced orbital MRI was not performed in the present typical GCA cases because GCA is mainly diagnosed based on fundus findings, the presence of systemic symptoms, laboratory findings, and a temporal artery biopsy. Enhancement of the ONS in contrast-enhanced MRI is an important finding for diagnosing optic perineuritis (OPN). ${ }^{21}$ OPN has generally been considered an idiopathic disease, but it occasionally occurs as a manifestation of specific infectious, systemic inflammatory disorders or GCA..$^{21-26}$ However, Morotti et al. ${ }^{25}$ suggested that ONS enhancement related to GCA may be underestimated due to the atypical clinical features of GCA and since corticosteroid therapy tends to be introduced early before GCA has been confirmed pathologically. Most cases of OPN exhibit dramatic improvement after steroid treatment, ${ }^{21,22}$ whereas the cases of ONS enhancement with GCA in the literature ${ }^{24,25}$ as well as those in the current study did not respond to steroid treatment. This suggests that optic nerve damage in GCA with ONS enhancement is linked to not only ONS autoinflammation but also ischemic damage to the optic nerve. However, Liu and Miller ${ }^{27}$ reported that cases of unilateral AAION associated with GCA exhibited bilateral ONS enhancement in contrast-enhanced MRI. We experienced a similar finding in case 6 , but we could not conclude the prevalence of ONS enhancement associated with GCA, and the possibility of GCA should be considered in patients with presumed OPN exhibiting a poor response to steroid treatment, elevated ESR, pale optic disc swelling combined with retinal artery narrowing, or systemic symptoms related to GCA.

All of our patients received steroid treatment, but this resulted in improvement in only one of them, with most patients having poor final visual outcomes. This finding is similar to previous reports..$^{28-33}$ However, $>50 \%$ of our Korean patients with AAION associated with GCA had bilateral involvement. Although we could not identify the true incidence of bilateral involvement in our Korean patients with AAION due to the small number of included patients, our findings highlight 


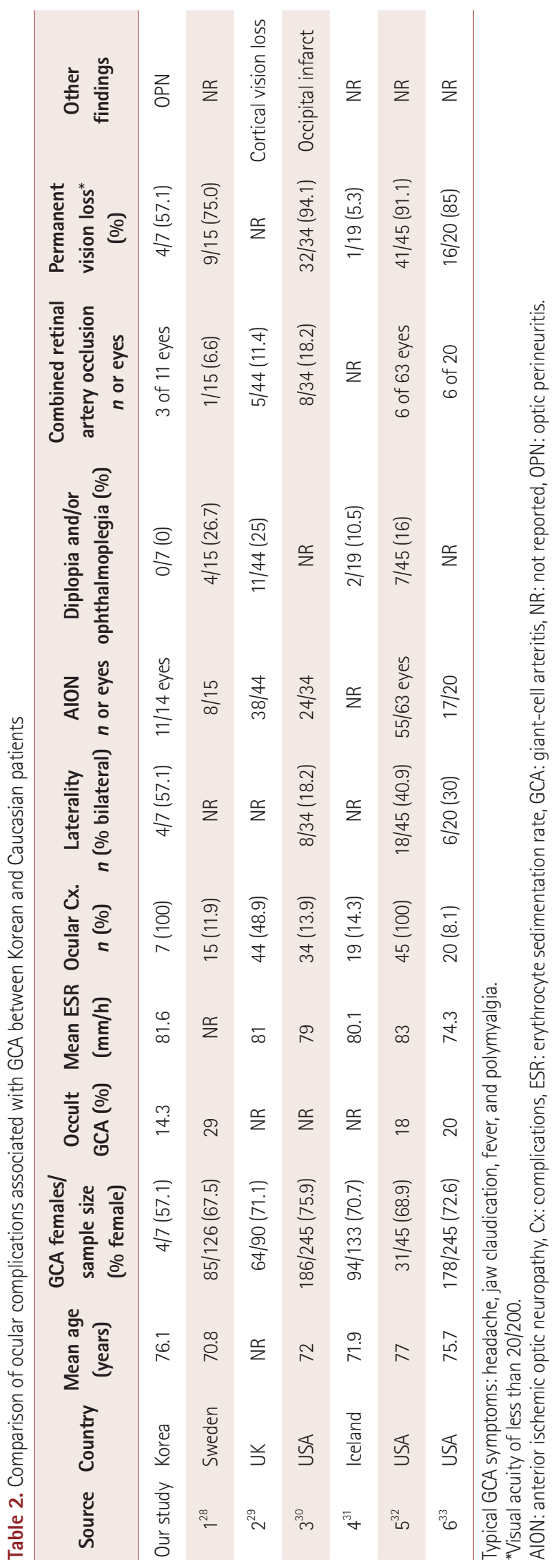

that AAION associated with GCA needs to be treated promptly, and it may still cause permanent bilateral vision loss.

Our study was subject to several limitations. We only investigated a small number of patients whose exact medical history was not available in the literature; however, most of the patients in this study did have biopsy-confirmed GCA. We could not report the incidence and morbidity rates of AAION associated with GCA in our Korean population, and so our study could only address the ratio of AAION-to-NAION cases. We also could not conduct statistical comparisons between AAION and NAION in our Korean population, but the prevalence of AAION was much lower than that of NAION. Cardiovascular risk factors, a small optic disc, and obstructive sleep apnea have been strongly associated with NAION..$^{34-36}$ We therefore suggest that a further study involving a large population survey is needed to determine the genetic association and/ or environment influences in AAION and/or NAION among different races. An additional drawback of our study is that we limited our analysis to a literature review and comparison. One striking finding was that the clinical manifestations of GCA in our Korean population were similar to those in our Caucasian population. Moreover, we found that prompt diagnosis and early treatment are also very important for preventing permanent and sometimes bilateral vision loss in Korean patients.

In conclusion, AAION associated with GCA is a very rare condition in Korea. However, GCA should be considered in cases of ischemic optic neuropathy because AAION patients have poor visual outcomes, which sometimes occur bilaterally.

\section{Conflicts of Interest}

The authors have no potential conflicts of interest to disclose.

\section{REFERENCES}

1. Weyand CM, Goronzy JJ. Giant-cell arteritis and polymyalgia rheumatica. Ann Intern Med 2003;139:505-515.

2. Rahman W, Rahman FZ. Giant cell (temporal) arteritis: an overview and update. Surv Ophthalmol 2005;50:415-428.

3. Hayreh SS, Podhajsky PA, Zimmerman B. Occult giant cell arteritis: ocular manifestations. Am J Ophthalmol 1998;125:521-526.

4. Hayreh SS. Ischemic optic neuropathy. Prog Retin Eye Res 2009;28:3462.

5. Pereira LS, Yoon MK, Hwang TN, Hong JE, Ray K, Porco T, et al. Giant cell arteritis in Asians: a comparative study. Br J Ophthalmol 2011; 95:214-216.

6. Kobayashi S, Yano T, Inaba Y, Hashimoto H, Matsumoto Y, Tamakoshi A, et al. Ocular involvements of Japanese patients with giant cell arteritis from the first nation-wide survey. Arthritis Rheum 2003;49:867868.

7. Cha DM, Lee T, Choe G, Yang HK, Hwang JM. Silent giant cell arteritis in an elderly Korean woman. Korean J Ophthalmol 2013;27:224-227.

8. Kang YS, Park SW, Lee HK, Choi YD, Heo H. Arteritic anterior ischemic optic neuropathy associated with giant cell arteritis in an elderly Korean man. Korean J Ophthalmol 2016;30:239-241.

9. Yoon HJ, Park SW, Lee HK, Choi YD, Heo H. Bilateral arteritic anteri- 
or ischemic optic neuropathy associated with giant cell arteritis in Korea. Korean J Ophthalmol 2017;31:466-467.

10. Lee SM, Shin DH, Choi JH, Jung JH. A case of bilateral arteritic anterior ischemic optic neuropathy in Korean patient. Clin Neuroophthalmol 2018;8:9-12.

11. Lee EJ, Woo KA, Koo DL. Giant cell arteritis associated arteritic anterior ischemic optic neuropathy: sudden vision loss on the contralateral side of headache. J Clin Neurol 2018;14:577-579.

12. Miller NR. Anterior ischemic optic neuropathy: diagnosis and management. Bull N Y Acad Med 1980;56:643-654.

13. Miller NR, Arnold AC. Current concepts in the diagnosis, pathogenesis and management of nonarteritic anterior ischaemic optic neuropathy. Eye (Lond) 2015;29:65-79.

14. Hunder GG, Bloch DA, Michel BA, Stevens MB, Arend WP, Calabrese LH, et al. The American College of Rheumatology 1990 criteria for the classification of giant cell arteritis. Arthritis Rheum 1990;33:1122-1128.

15. Hayreh SS. Ischemic optic neuropathies-where are we now? Graefes Arch Clin Exp Ophthalmol 2013;251:1873-1884.

16. Gruener AM, Chang JR, Bosley TM, Al-Sadah ZM, Kum C, McCulley TJ. Relative frequencies of arteritic and nonarteritic anterior ischemic optic neuropathy in an Arab population. J Neuroophthalmol 2017;37: 382-385.

17. Tatò F, Hoffmann U. Giant cell arteritis: a systemic vascular disease. Vasc Med 2008;13:127-140.

18. Nuenninghoff DM, Hunder GG, Christianson TJ, McClelland RL, Matteson EL. Incidence and predictors of large-artery complication (aortic aneurysm, aortic dissection, and/or large-artery stenosis) in patients with giant cell arteritis: a population-based study over 50 years. Arthritis Rheum 2003;48:3522-3531.

19. Currey J. Scalp necrosis in giant cell arteritis and review of the literature. Br J Rheumatol 1997;36:814-816.

20. Tsianakas A, Ehrchen JM, Presser D, Fischer T, Kruse-Loesler B, Luger TA, et al. Scalp necrosis in giant cell arteritis: case report and review of the relevance of this cutaneous sign of large-vessel vasculitis. J Am Acad Dermatol 2009;61:701-706.

21. Purvin V, Kawasaki A, Jacobson DM. Optic perineuritis: clinical and radiographic features. Arch Ophthalmol 2001;119:1299-1306.

22. Hickman SJ. Optic perineuritis. Curr Neurol Neurosci Rep 2016;16:16.

23. Byon IS, Jung JH, Kim HY, Park SW, Lee JE. Optic perineuritis secondary to acute retinal necrosis. J Neuroophthalmol 2013;33:419-421.

24. Morgenstern KE, Ellis BD, Schochet SS, Linberg JV. Bilateral optic nerve sheath enhancement from giant cell arteritis. J Rheumatol 2003;
30:625-627.

25. Morotti A, Liberini P, Padovani A. Bilateral optic perineuritis as the presenting feature of giant cell arteritis. BMJ Case Rep 2013;2013:bcr2011 007959.

26. Attaseth T, Vanikieti K, Poonyathalang A, Preechawat $\mathrm{P}$, Jindahra $\mathrm{P}$, Wattanatranon D. Anterior ischemic optic neuropathy due to biopsyproven giant cell arteritis in Thai patients. Clin Ophthalmol 2015;9: 1071-1075.

27. Liu TY, Miller NR. Giant cell arteritis presenting as unilateral anterior ischemic optic neuropathy associated with bilateral optic nerve sheath enhancement on magnetic resonance imaging. J Neuroophthalmol 2015;35:360-363.

28. Bengtsson BA, Malmvall BE. The epidemiology of giant cell arteritis including temporal arteritis and polymyalgia rheumatica. Incidences of different clinical presentations and eye complications. Arthritis Rheum 1981;24:899-904.

29. Graham E, Holland A, Avery A, Russell RW. Prognosis in giant-cell arteritis. Br Med J (Clin Res Ed) 1981;282:269-271.

30. Aiello PD, Trautmann JC, McPhee TJ, Kunselman AR, Hunder GG. Visual prognosis in giant cell arteritis. Ophthalmology 1993;100:550555.

31. Baldursson O, Steinsson K, Björnsson J, Lie JT. Giant cell arteritis in Iceland. An epidemiologic and histopathologic analysis. Arthritis Rheum 1994;37:1007-1012.

32. Liu GT, Glaser JS, Schatz NJ, Smith JL. Visual morbidity in giant cell arteritis. Clinical characteristics and prognosis for vision. Ophthalmology 1994;101:1779-1785.

33. Chen JJ, Leavitt JA, Fang C, Crowson CS, Matteson EL, Warrington $\mathrm{KJ}$. Evaluating the incidence of arteritic ischemic optic neuropathy and other causes of vision loss from giant cell arteritis. Ophthalmology 2016;123:1999-2003.

34. Giambene B, Sodi A, Sofi F, Marcucci R, Fedi S, Abbate R, et al. Evaluation of traditional and emerging cardiovascular risk factors in patients with non-arteritic anterior ischemic optic neuropathy: a casecontrol study. Graefes Arch Clin Exp Ophthalmol 2009;247:693-697.

35. Arda H, Birer S, Aksu M, Ismailogullari S, Karakucuk S, Mirza E, et al. Obstructive sleep apnoea prevalence in non-arteritic anterior ischaemic optic neuropathy. Br J Ophthalmol 2013;97:206-209.

36. Kim DH, Shin GR, Choi YJ. Risk factors for non-arteritic anterior ischaemic optic neuropathy in a Korean population. Neuroophthalmology 2017;41:68-75. 